\title{
Early Improvement and Marriage Are Determinants of the 12-Month Treatment Outcome of Paroxetine in Outpatients with Panic Disorder
}

\author{
Takashi Watanabe ${ }^{1}$, Mikito Ueda ${ }^{1}$, Shin Ishiguro ${ }^{1}$, Yuki Hayashi ${ }^{1}$, Akiko Aoki ${ }^{1}$, Masataka Shinozaki ${ }^{1}$, \\ Kazuko Kato ${ }^{3}$, Kazufumi Akiyama ${ }^{2}$, Kazutaka Shimoda ${ }^{1}$ \\ ${ }^{1}$ Department of Psychiatry, ${ }^{2}$ Department of Biological Psychiatry and Neuroscience, Dokkyo Medical University School of Medicine, Shimotsuga, \\ ${ }^{3}$ Mental Health Clinic SAKURA-RA, Utsunomiya, Japan
}

\begin{abstract}
Objective: In this study, we investigated the determinants of remission and discontinuation of paroxetine pharmacotherapy in outpatients with panic disorder (PD).

Methods: Subjects were 79 outpatients diagnosed with PD who took 10-40 mg/day of paroxetine for 12 months. The candidate therapeutic determinants included the serotonin transporter gene-linked polymorphic region and the $-1019 \mathrm{C} / \mathrm{G}$ promoter polymorphism of the serotonin receptor $1 \mathrm{~A}$ as genetic factors, educational background and marital status as environmental factors, and early improvement (El) at 2 weeks as a clinical factor were assessed. The Clinical Global Impression scale was used to assess the therapeutic effects of the pharmacotherapy.

Results: Cox proportional hazards regression was performed to investigate the significant predictive factors of remission and discontinuation. El was only a significant predictive factor of remission. El was a significant predictive factor of remission (hazard ratio $[\mathrm{HR}], 2.709 ; 95 \%$ confidence interval $[\mathrm{Cl}], 1.177-6.235)$. Otherwise, El and marital status were significant predictive factors of the discontinuation. El ( $\mathrm{HR}, 0.266 ; 95 \% \mathrm{Cl}, 0.115-0.617)$ and being married (HR, 0.437; 95\% Cl, 0.204-0.939) were considered to reduce the risk of treatment discontinuation. In married subjects, El was a significant predictive factor of the discontinuation (HR, 0.160; 95\% Cl, 0.045-0.565). However, in unmarried subjects, El was not a significantly predictive factor for the discontinuation.

Conclusion: El achievement appears to be a determinant of PD remission in paroxetine treatment. In married PD patients, El achievement also appears to reduce a risk of discontinuation of paroxetine treatment.
\end{abstract}

KEY WORDS: Paroxetine; Panic disorder; Marital status; Treatment outcome; Patient dropouts; Induction of remission.

\section{INTRODUCTION}

Panic disorder (PD) is considered to be familial and heritable. In a recent epidemiological survey, lifetime prevalence estimates were $22.7 \%$ for isolated panic attacks without agoraphobia, $0.8 \%$ for panic attacks with agoraphobia without PD, $3.7 \%$ for PD without agoraphobia, and $1.1 \%$ for PD with agoraphobia. ${ }^{1)}$ There is a clear sex difference, with a female:male ratio of 2.55.6:1. ${ }^{2)}$ Family and twin studies have suggested a genetic liability for $\mathrm{PD}^{3-5)}$ and a meta-analysis estimated a heritability of $48 \%$ for PD. ${ }^{6}$ )

\footnotetext{
Received: January 2, 2017 / Revised: February 22, 2017

Accepted: March 18, 2017

Address for correspondence: Takashi Watanabe, MD, PhD Department of Psychiatry, Dokkyo Medical University School of Medicine, 880 Kitakobayashi, Mibu, Shimotsuga, Tochigi 321-0293, Japan

Tel: +81-282-86-1111(ext 7189), Fax: +81-282-86-5187

E-mail: takashiw@dokkyomed.ac.jp
}

Selective serotonin reuptake inhibitors (SSRIs) are thought to interact with the serotonergic nervous system and to be effective for treating PD. The primary target of SSRIs is the serotonin (5-HT) transporter (5-HTT), which removes 5-HT from the synaptic cleft. However, the therapeutic effects of SSRIs on anxiety disorders are thought to depend on stimulation of the postsynaptic 5-HT1A serotonin receptor in the amygdala. ${ }^{7,8)}$ In the amygdala, the expression of the postsynaptic 5-HT1A receptor might be largely rigid and unchangeable in adults. The report of Gross et al. ${ }^{9)}$ suggests that the amount of postsynaptic 5-HT1 A receptor expressed in the amygdala might be established in the developmental period, for example, during infancy or adolescence, and might be unchanged in adulthood.

The 5-HTT gene has been extensively screened for polymorphic variants. The 5-HTT gene-linked polymorphic region (5-HTTLPR), located in the promoter region, has

(c) This is an Open-Access article distributed under the terms of the Creative Commons Attribution Non-Commercial License (http://creativecommons.org/licenses/by-nc/4.0) which permits unrestricted non-commercial use, distribution, and reproduction in any medium, provided the original work is properly cited. 
been identified as a functional polymorphism. The polymorphism consists of a 44-base pair (bp) insertion or deletion involving 6 to 8 repeat elements. ${ }^{10)}$ In vitro, the basal activity of the long (L) variant is more than twice that of the short (S) one in terms of 5-HTT mRNA synthesis and 5-HTT expression. ${ }^{10)}$ These two different transcriptional efficiencies suggest that 5-HTT gene transcription is modulated by 5-HTTLPR genetic variants. ${ }^{10)}$ However, association studies have reported that there is no significant difference in 5-HTTLPR allele frequencies between individuals with PD and controls. ${ }^{11-14)}$ A systematic review and meta-analysis also failed to provide evidence to support an association between 5-HTTLPR and PD. ${ }^{15)}$

The $-1019 \mathrm{C} / \mathrm{G}$ (rs6295) promoter polymorphism of the 5-HT1A gene has been found to be associated with major depression and anxiety. ${ }^{16)}$ Freitag et al. ${ }^{17)}$ reported that the combination of the $-1019 \mathrm{C} / \mathrm{G}$ (rs6295) promoter gene and the COMT gene (472GA) is associated with PD, and especially PD without agoraphobia in Caucasians. Rothe et al $^{18)}$ reported a possible association between the mutated G allele of the $-1019 \mathrm{C} / \mathrm{G}$ 5-HT1A gene promoter polymorphism and $\mathrm{PD}$ with agoraphobia $(p=0.03$, $\mathrm{n}=101)$.

The complex genetic architecture of PD might include the effect of a genexenvironment interaction on PD development. Potential environmental factors included stressful life events, ${ }^{19-21)}$ or marital separation, ${ }^{21)}$ marital status $^{22)}$ are associated with PD. In addition, Manuck et $a l .^{23)}$ reported that socioeconomic status defined by levels of income, economic disadvantage, housing costs, and educational attainment also affects brain serotonergic function and psychiatric disorders. Recent gene $\times$ environment interaction studies have also provided evidence of the influence of environmental factors such as separation life events on PD development. ${ }^{24)}$ It is possible that separation life events or marital status might affect not only symptoms but also therapeutic outcome in PD.

Additionally, low educational background interacts with psychiatric disorders. ${ }^{25)}$ And it has been reported that smoking is associated with an increased risk of panic attacks. ${ }^{26)}$ A close relationship between alcohol use and PD has been suggested and brain white matter microstructural changes are associated with alcohol use in patients with PD. ${ }^{27)}$ Therefore, these factors might affect therapeutic outcome in PD.

Recent investigations have also focused on the impact of genetic polymorphisms in 5-HT-related genes on the clinical effect of SSRIs in PD patients because 5-HTT is the primary target of SSRIs. Perna et al. ${ }^{28)}$ investigated the relationship between an allelic variation in the 5-HTTLPR and the clinical response to paroxetine (PAX), one of the representative SSRIs, in 92 patients with PD who completed a treatment with variable doses of PAX for 12 weeks. L/L and L/S genotypes showed a better response to PAX than did the $\mathrm{S} / \mathrm{S}$ genotype $(p<0.03)$. This result emerged in the entire sample but was related to only female patients $(p<0.02)$. Yevtushenko et al. ${ }^{29)}$ reported an association in 102 PD patients between the clinical response to SSRIs (sertraline or PAX) and the 5-HT1A receptor $-1019 \mathrm{C} / \mathrm{G}$ polymorphism after 6 weeks of pharmacotherapy.

Early improvement (EI) with antidepressants has been reported to predict late outcomes in major depressive disorders (MDDs). According to a meta-analysis, ${ }^{30)}$ EI ( $\geq$ $20 \%$ score reduction from baseline on the 17 -item Hamilton Rating Scale for Depression [HAM-D] within 2 weeks of treatment) with antidepressant medication could predict subsequent treatment outcomes (response and remission after 4 or 8 weeks) with sensitivities of $\geq 81 \%$ and $\geq 87 \%$, respectively) in patients with MDD (Diagnostic and Statistical Manual of Mental Disorder [DSM] III-R or DSM-IV criteria). In addition, Cusin et al. ${ }^{31)}$ reported that early clinical worsening is associated with a decreased likelihood of achieving remission in outpatients diagnosed with a DSM-III-R - defined major depressive episode and treated with fluoxetine $(20 \mathrm{mg} /$ day $)$ for up to 12 weeks. Gene $\times$ early partial improvement $(\geq 20 \%$ score reduction from baseline on the 21-item HAM-D within 2 weeks of treatment) interaction studies have also provided evidence of the influence of the interactions between candidate genes including 5-HTTLPR, - 1019C/G (rs6295), and early partial improvement and the outcome (percent change in HAM-D at 6 weeks) of treatment of SSRIs and a serotonin-norepinephrine reuptake inhibitor, milnacipran. ${ }^{32)}$

The purpose of the present study was to determine whether serotonin-related genes (5-HTTLPR, - 1019C/G), environmental factors, alcohol, smoking and EI affect the 12-month clinical course of PAX treatment in outpatients with PD.

\section{METHODS}

\section{Patients}

Patients were recruited to this study from July 13, 2004 to February 16, 2012. Seventy-nine unrelated Japanese patients who met the DSM fourth edition, text revision (DSM-IV-TR; American Psychiatric Association, Arlington, 2000) criteria for PD diagnosis and who were receiving 
PAX (paroxetine HCl; Paxil, GlaxoSmithKline K.K., Tokyo, Japan) were investigated.

Patients were excluded from the study for the following reasons: (1) Axis I diagnosis other than PD or MDD; (2) Axis II diagnosis; (3) severe physical illness or major laboratory test abnormalities; (4) suicide risk; (5) history of substance abuse; (6) use of antidepressants, antipsychotics, benzodiazepines, or 5-HT agonists before study entry; (7) pregnancy.

Written informed consent was obtained from each subject after a full explanation of the procedure. The Ethics Committee of Dokkyo Medical University Hospital (approval number 1948) and Mental Health Clinic SAKURA-RA (approval number 1) approved this study. PAX pharmacotherapy, evaluation of PD symptoms, and routine blood sampling tests, including blood cell count, liver function, renal function, electrolytes, urinalysis, blood sugar, and thyroid function were performed at the first hospital visit.

\section{Treatment}

For the first 4 weeks, subjects were administered PAX $(10 \mathrm{mg} /$ day $)$ at bedtime. For the next 4 weeks, the clinician could increase PAX to $20 \mathrm{mg}$ /day if patients could tolerate the higher dose. Two months after the start of the treatment, PAX could be increased to $40 \mathrm{mg}$ /day if tolerated. Subjects were required to maintain a minimum daily dose of PAX (10 mg/day). Subjects who could not tolerate the minimum daily dose of PAX and switched to another medication were withdrawn from the study. Subjects with insomnia were prescribed brotizolam 0.25 or $0.5 \mathrm{mg}$ at bedtime, and subjects were permitted to take low doses of lorazepam $(<2.0 \mathrm{mg} /$ day $)$ when they experienced a panic attack.

\section{Clinical Assessment}

The Clinical Global Impression scale ${ }^{33)}$ was used by an experienced psychiatrist to assess severity and improvement of PD. The Clinical Global Impression-Severity (CGI-S) assessment, which is rated on the a 7-point scale (1=normal, not at all ill; $2=$ borderline mentally ill; $3=$ mildly ill; $4=$ moderately ill; $5=$ markedly ill; $6=$ severely ill; $7=$ among the most extremely ill patients), was used to assess severity at baseline, 2 weeks, 1 month, 2 months, 3 months, 6 months, and 12 months. CGI-S scores of 1 (normal, not at all ill) and 2 (borderline mentally ill) were defined as remission, and the proportion of patients in remission was calculated. The Clinical Global ImpressionImprovement (CGI-I), which is rated on a 7-point scale
( $1=$ very much improved since the initiation of treatment; $2=$ much improved; $3=$ minimally improved; $4=$ no change from baseline [the initiation of treatment]; $5=$ minimally worse; $6=$ much worse; $7=$ very much worse since the initiation of treatment), was used to assess improvement at 2 weeks, 1 month, 2 months, 3 months, 6 months, and 12 months. EI was defined as follows: a CGI-I score of 1 (very much improved), 2 (much improved), or 3 (minimally improved) at 2 weeks.

\section{Sampling}

Seven milliliters of venous blood was collected from all patients into Venoject tubes containing EDTA-Na (Terumo Japan, Tokyo, Japan). Samples were centrifuged at 3,000 $\times g$ for 10 minutes, and aliquots of plasma and cell fractions were separated and frozen at $-80^{\circ} \mathrm{C}$ until analysis. The procedure of the present study was different from that of our previous studies ${ }^{34,35)}$ in that the PAX plasma concentration was not determined in this study.

\section{Environmental Factors and Other Information}

Patients were also interviewed about environmental factors such as educational background, marital status (being married or being never married and marital separation; separated, divorced, or widowed), and other information including habitual use of alcohol, smoking, and comorbid physical illnesses. The marital status was categorized in details as follows: married, never married, divorced, separated, or widowed. ${ }^{36)}$

\section{Genotyping}

DNA was isolated from blood cell fractions using the QIAamp Blood kit (QIAGEN, Hilden, Germany). The 5-HTTLPR genotypes (L and S alleles) were determined by polymerase chain reaction (PCR) as described by Lesch et al. ${ }^{37)}$ and Heils et al. ${ }^{10)}$ with minor modifications. Oligonucleotide primers flanking the 5-HTTLPR and corresponding to nucleotide positions -1416 to -1397 (LPR5; 5'-GGCGTTGCCGCTCTGAATTGC) and -910 to -889 (LPR3; 5'-GAGGGACTGAGCTGGACAACC $\mathrm{CAC}$ ) of the 5-HTT gene regulatory region were used to generate a 484-/528-bp fragment. PCR amplification was carried out in a final volume of $12.5 \mu \mathrm{l}$ containing $20 \mathrm{ng}$ genomic DNA, $0.8 \mathrm{mM}$ dNTP mixture, $0.05 \mu \mathrm{g}$ sense and antisense primers (LPR5 and LPR3), $1 \times$ PCR buffer, 1.5 $\mathrm{mM} \mathrm{MgCl} 2,5 \%$ dimethyl sulfoxide, and $0.5 \mathrm{U}$ AmpliTaq DNA polymerase (Applied Biosystems, Foster City, CA, USA). The PCR conditions consisted of 35 cycles of annealing at $60^{\circ} \mathrm{C}$ for 30 seconds, extension at $72^{\circ} \mathrm{C}$ for $1 \mathrm{mi}$ - 
nute, and denaturation at $94^{\circ} \mathrm{C}$ for 30 seconds.

The rs6295 single nucleotide polymorphism (SNP) in the 5-HT1A receptor gene was analyzed using TaqMan SNP Genotyping Assays (Assay ID: C_11904666_10; Applied Biosystems). PCR amplification was performed in a total volume of $10 \mu \mathrm{l}$ containing $1 \times \mathrm{LA}$ PCR buffer, $2.5 \mathrm{mM} \mathrm{MgCl}_{2}, 0.25 \mathrm{mM}$ of each dNTP, $1 \times$ TaqMan probe (Applied Biosystems), $20 \mathrm{ng}$ genomic DNA, and $0.5 \mathrm{U}$ TaKaRa LA Taq (Takara Bio, Otsu, Japan) in a TP800 Thermal Cycler Dice Real-Time System (Takara Bio). FAM-MBG dyes were detected as the major allele and VIC-MBG dyes as the minor allele. The PCR conditions were $95^{\circ} \mathrm{C}$ for 1 minute 45 seconds, followed by 40 cycles of $92^{\circ} \mathrm{C}$ for 15 seconds and $60^{\circ} \mathrm{C}$ for 1 minute.

\section{Statistical Analysis}

A Cox proportional hazards model was used to assess the significance of predictors of time to remission and treatment discontinuation from the start of the treatment. Dummy variables were given for $\operatorname{sex}($ female $=0$, male $=1$ ) and habitual use of alcohol (non-user $=0$, user $=1$ ), smoking habit (nonsmoker $=0$, smoker $=1$ ), educational background (graduate of high school or less $=0$, graduate of college or university $=1$ ), marital status (unmarried $=0$, married=1), marital separation (separated, divorced, or widowed $=1$, without separation $=0$ ), comorbid physical illness (without physical illness $=0$, with physical illness $=1$ ), comorbid MDD (without $\mathrm{MDD}=0$, with $\mathrm{MDD}=1$ ), comorbid agoraphobia (without agoraphobia $=0$, with agoraphobia=1), 5-HTTLPR genotype $(\mathrm{L} / \mathrm{S}$ and $\mathrm{L} / \mathrm{L}=1$, $\mathrm{S} / \mathrm{S}=0)$, and $-1019 \mathrm{C} / \mathrm{G} 5$-HT1A genotype $(\mathrm{C} / \mathrm{C}=1, \mathrm{C} / \mathrm{G}$ and $\mathrm{G} / \mathrm{G}=0)$, $\mathrm{EI}(\mathrm{EI}=1$, non- $\mathrm{EI}=0)$ as independent variables. Time to remission and treatment discontinuation from the start of the treatment was measured and analyzed by Kaplan-Meier survival analysis (log-rank method). Stepwise multiple regression analysis, multiple logistic regression analysis, and chi-square test were also used. All statistical tests were two-tailed, and $p$ values of $<0.05$ were considered significant. Statistical analyses were conducted using IBM SPSS statistics software version 23.0 (Japan IBM, Tokyo, Japan).

\section{RESULTS}

The subjects ( 30 men and 49 women; age, $35.4 \pm 10.6$ years; age range, 20-72 years) were psychiatric outpatients at Dokkyo Medical University Hospital $(n=61)$ and Mental Health Clinic SAKURA-RA $(n=18)$. The body weights of the patients ranged from 40 to $95 \mathrm{~kg}$
$(58.0 \pm 11.0 \mathrm{~kg})$. Subject characteristics are shown in Table 1. Thirteen patients had comorbid MDD. Twenty-three patients were smokers (number of cigarettes per day, 15.0 \pm 7.4 ; range, 5-40). Fifty subjects were married. And 23 subjects were never married, 6 subjects were unmarried with marital separation ( separated $=1$, divorced $=3$, widowed=2). Regarding educational background, 46 subjects had an education level of high school graduate or less, and 33 subjects were college or university graduates. The 5-HTTLPR $(\mathrm{L} / \mathrm{L}=3, \mathrm{~L} / \mathrm{S}=26, \mathrm{~S} / \mathrm{S}=50)$ and $-1019 \mathrm{C} / \mathrm{G}$ 5-HT1A $(\mathrm{C} / \mathrm{C}=35, \mathrm{C} / \mathrm{G}=39, \mathrm{G} / \mathrm{G}=5)$ genotypes were determined for each subject.

Stepwise multiple regression analysis was performed to analyze the relationship between independent variables (sex, age, body weight, smoking habit, habitual use of alcohol, educational background, marital status, marital separation, comorbid physical illness, comorbid MDD, comorbid agoraphobia, 5-HTTLPR genotype, 5HT1A -1019 genotype) and the subject-dependent variable (CGI-S score at baseline). The stepwise multiple regression analysis revealed that comorbid MDD, marital status, and 5-HTTLPR genotype were significant factors, and $\mathrm{R}$ for the full model was 0.525 , indicating that these factors accounted for $27.6 \%$ (coefficient of determination $\left[\mathrm{R}^{2}\right]=0.276$ ) of the variability of the CGI-S score at baseline. The final model was described by the following equation $(p<0.001)$ : CGI-S score at baseline $=4.028$ $+1.069 \times($ without $\mathrm{MDD}=0$, with $\mathrm{MDD}=1)+0.452 \times$ (unmarried $=0$, married $=1$ ) $-0.404 \times(\mathrm{L} / \mathrm{S}$ and $\mathrm{L} / \mathrm{L}=1, \mathrm{~S} / \mathrm{S}=0$ ).

The study flowchart is shown in Figure 1. Fifty-two patients $(65.8 \%)$ achieved remission during the 12 months. Three patients worsened after they achieved remission but the other patients did not worsen after they achieved remission. According to Kaplan-Meier survival analysis,

Table 1. Characteristics of the sample

\begin{tabular}{lc}
\multicolumn{1}{c}{ Characteristic } & Data \\
\hline Number of patients & 79 \\
Male/female & $39 / 40$ \\
Age (yr) & $35.4 \pm 10.6$ \\
Body weight (kg) & $58.0 \pm 11.0$ \\
With/without MDD & $13 / 66$ \\
With/without agoraphobia & $63 / 16$ \\
CGl-S at baseline & $4.34 \pm 0.86$ \\
With/without physical illness & $23 / 56$ \\
Married/unmarried & $50 / 29$ \\
Smoker/nonsmoker & $23 / 56$ \\
Habitual user of alcohol/non-user & $10 / 69$ \\
\hline
\end{tabular}

Data are expressed as number only or mean \pm standard deviation. MDD, major depressive disorder; CGI-S, the Clinical Global Impression-Severity. 


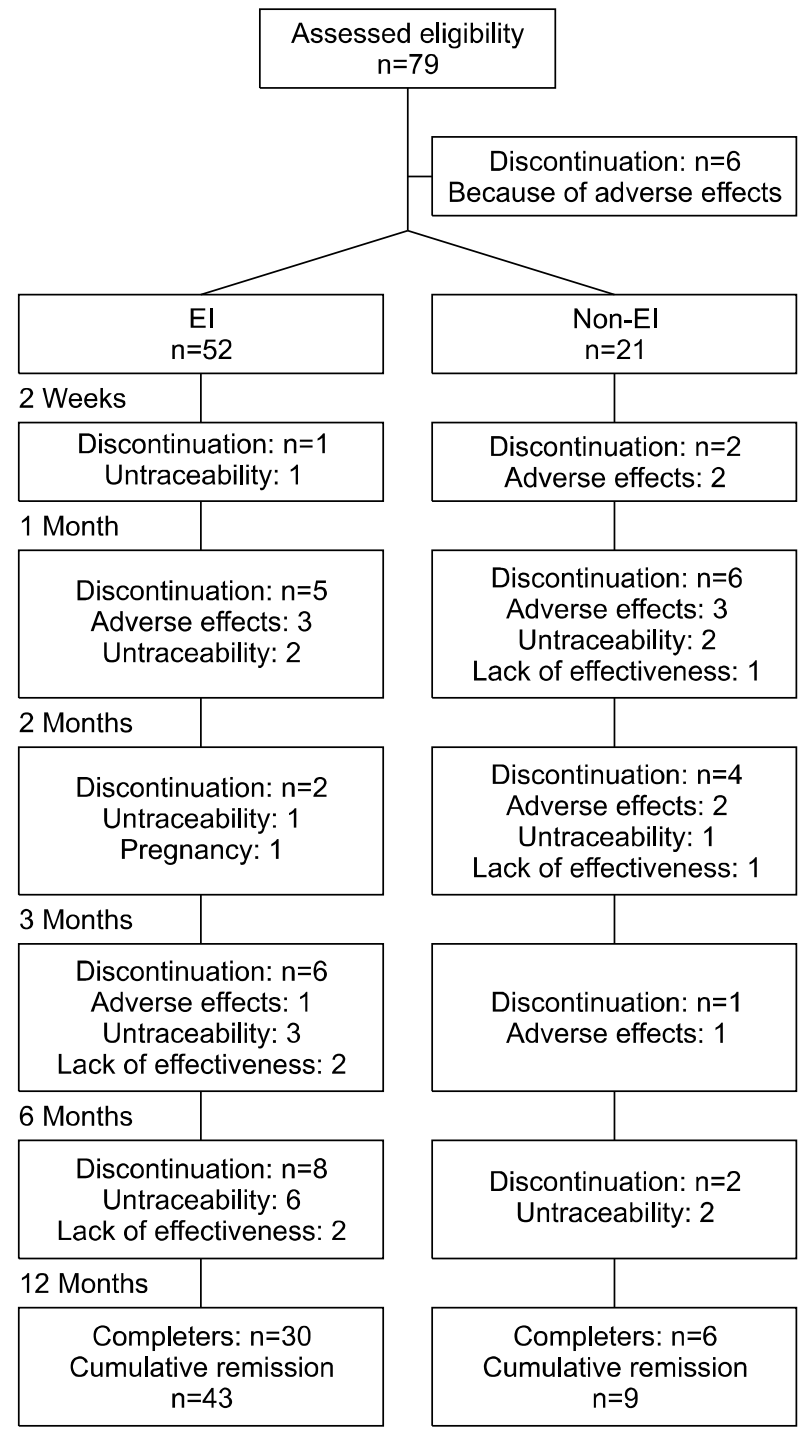

Fig. 1. Study flowchart. El, early improvement. the mean time to remission was 4.433 months $(95 \%$ confidence interval $[\mathrm{CI}], 3.334-5.532)$ and the $50 \%$ median survival time to treatment remission was 2.000 months (95\% CI, 1.638-2.362). Additionally, 43 patients (54.4\%) discontinued the treatment during the 12-month study period. Kaplan-Meier survival analysis revealed that the mean time to discontinuation was 8.101 months $(95 \% \mathrm{CI}$, $7.038-9.164)$ and that the $50 \%$ median survival time to treatment discontinuation was over 12 months.

At 2 weeks, six patients discontinued the treatment because of severe adverse effects (nausea $=2$, daytime drowsiness $=2$, diarrhea $=1$, abnormal sensation $=1$ ). Thus, 73 patients continued the treatment: 52 obtained EI ( 7 patients achieved remission) and 21 failed to achieve EI at 2 weeks. Multiple logistic regression analysis was performed to assess the association between independent variables (sex, smoking habit, habitual use of alcohol, educational background, marital status, marital separation, comorbid physical illness, comorbid MDD, comorbid agoraphobia, 5-HTTLPR genotype, and rs6295 genotype) and the subject-dependent variable (EI). Multiple logistic regression analysis revealed that smoking habit had a significantly negative correlation with EI $(p=0.010)$. Smoking was a risk factor for failure to achieve EI, with an odds ratio to EI of 0.16 (95\% CI, 0.041-0.647).

Cox proportional hazards regression was performed to investigate the significant predictive factors of remission and discontinuation among covariates: sex, smoking habit, habitual use of alcohol, educational background, marital status, marital separation, comorbid physical illness, comorbid MDD, comorbid agoraphobia, 5-HTTLPR genotype, rs6295 genotype, and EI. EI was only a significant predictive factor of remission (Table 2, Fig. 2). EI group was 2.7 times more likely to get remission than non-EI

Table 2. Cox proportional hazards regression to investigate factors predicting remission

\begin{tabular}{|c|c|c|c|c|c|c|}
\hline Covariate & Coefficient & SE & Wald & $p$ value & $H R$ & $95 \% \mathrm{Cl}$ \\
\hline Sex & 0.144 & 0.350 & 0.170 & 0.680 & 1.155 & $0.582-2.292$ \\
\hline Educational background & -0.114 & 0.313 & 0.131 & 0.717 & 0.893 & $0.483-1.649$ \\
\hline Marriage & -0.137 & 0.366 & 0.140 & 0.708 & 0.872 & $0.426-1.787$ \\
\hline Marital separation & 0.933 & 0.828 & 1.270 & 0.260 & 2.542 & $0.502-12.876$ \\
\hline With agoraphobia & -0.533 & 0.369 & 2.085 & 0.149 & 0.587 & $0.284-1.210$ \\
\hline Comorbid major depressive disorder & -0.695 & 0.509 & 1.866 & 0.172 & 0.499 & $0.184-1.353$ \\
\hline Comorbid physical illness & -0.051 & 0.330 & 0.024 & 0.877 & 0.950 & $0.498-1.813$ \\
\hline Habitual use of alcohol & -0.047 & 0.423 & 0.012 & 0.912 & 0.955 & $0.417-2.186$ \\
\hline Smoking habit & -0.013 & 0.370 & 0.001 & 0.972 & 0.987 & $0.478-2.040$ \\
\hline 5-HTTLPR L/L, L/S genotypes & 0.177 & 0.339 & 0.272 & 0.602 & 1.193 & $0.614-2.317$ \\
\hline 5-HT1A rs 6295 C/C genotype & 0.286 & 0.317 & 0.814 & 0.367 & 1.331 & $0.715-2.477$ \\
\hline Early improvement & 0.997 & 0.425 & 5.491 & $0.019^{*}$ & 2.709 & $1.177-6.235$ \\
\hline
\end{tabular}

SE, standard error; HR, hazard ratio; $95 \% \mathrm{Cl}, 95 \%$ confidence interval; L, long; S, short. ${ }^{*} p<0.05$. 
group (hazard ratio [HR], 2.709; 95\% CI, 1.177-6.235).

Otherwise, EI and marital status were significant predictive factors of discontinuation (Table 3). EI (HR, 0.266; 95\% CI, 0.115-0.617) and being married (HR, 0.437 ; $95 \%$ CI, $0.204-0.939$ ) were considered to reduce the risk of discontinuation of the treatment (Figs. 3, 4). In married subjects, Subjects with EI were 0.16 times more likely to get discontinuation of the treatment than Subjects without EI ( $p=0.004, \mathrm{HR}, 0.160 ; 95 \%$ CI, 0.045-0.565). However, in unmarried subjects, Subjects with EI were not significantly more likely to get discontinuation of the treatment than Subjects without EI ( $p=0.149$, HR, 0.363; 95\% CI, 0.092-1.439).

In the EI group, 13 patients discontinued the treatment after they achieved remission. In the non-EI group, 3 patients did so.

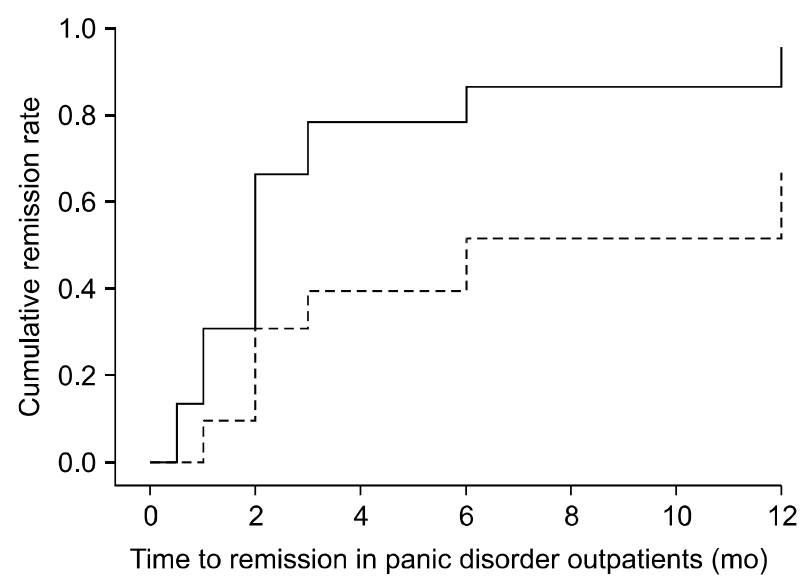

Fig. 2. Cox regression analysis for remission during 12 months of paroxetine treatment in early improvement (EI) group (solid line) and non-El group (dotted line).

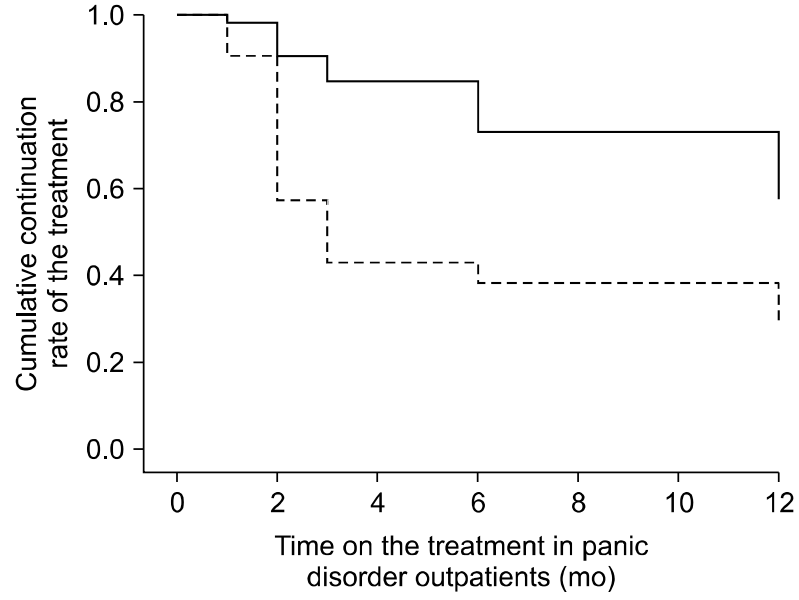

Fig. 3. Cox regression analysis for treatment discontinuation during 12 months of paroxetine treatment in early improvement (EI) group (solid line) and non-El group (dotted line).

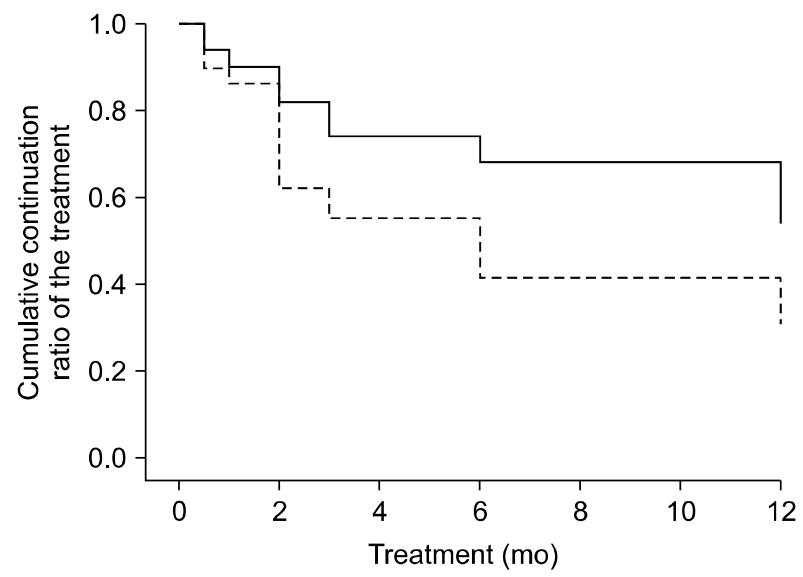

Fig. 4. Cox regression analysis oftreatment discontinuation during 12 months of paroxetine treatment by marital status. The cumulative continuation ratewas significantly higher in married subjects (solid line) than in unmarried subjects (dotted line).

Table 3. Cox proportional hazards regression to investigate factors predicting discontinuation

\begin{tabular}{|c|c|c|c|c|c|c|}
\hline Covariates & Coefficient & SE & Wald & $p$ value & $H R$ & $95 \% \mathrm{Cl}$ \\
\hline Sex & -0.443 & 0.405 & 1.194 & 0.274 & 0.642 & $0.290-1.421$ \\
\hline Educational background & 0.636 & 0.387 & 2.694 & 0.101 & 1.888 & $0.884-4.033$ \\
\hline Marriage & -0.827 & 0.390 & 4.501 & $0.034^{*}$ & 0.437 & 0.204-0.939 \\
\hline Marital separation & 0.614 & 0.709 & 0.751 & 0.386 & 1.848 & $0.461-7.413$ \\
\hline With agoraphobia & -0.064 & 0.423 & 0.023 & 0.879 & 0.938 & $0.409-2.149$ \\
\hline Comorbid major depressive disorder & 0.486 & 0.519 & 0.874 & 0.350 & 1.625 & $0.587-4.497$ \\
\hline Comorbid physical illness & -0.299 & 0.382 & 0.616 & 0.433 & 0.741 & $0.351-1.566$ \\
\hline Habitual use of alcohol & 0.847 & 0.538 & 2.476 & 0.116 & 2.333 & $0.812-6.700$ \\
\hline Smoking habit & 0.255 & 0.456 & 0.313 & 0.576 & 1.291 & $0.528-3.153$ \\
\hline 5-HTTLPR L/L, L/S genotypes & 0.086 & 0.420 & 0.042 & 0.838 & 1.090 & $0.478-2.485$ \\
\hline 5-HT1A rs 6295 C/C genotype & 0.133 & 0.370 & 0.128 & 0.720 & 1.142 & $0.553-2.360$ \\
\hline Early improvement & -1.324 & 0.429 & 9.527 & $0.002^{*}$ & 0.266 & $0.115-0.617$ \\
\hline
\end{tabular}

SE, standard error; HR, hazard ratio; $95 \% \mathrm{Cl}, 95 \%$ confidence interval; L, long; S, short. ${ }^{*} p<0.05$. 


\section{DISCUSSION}

Yevtushenko et al. ${ }^{29)}$ reported a significant association of the 5-HT1A receptor $-1019 \mathrm{C} / \mathrm{G}$ polymorphism with the clinical response to SSRIs (sertraline or PAX) after 6 weeks of pharmacotherapy in 102 PD patients. In their study, 20 subjects of the $\mathrm{G} / \mathrm{G}$ genotype showing minimal changes in panic attack frequency with a relative risk of no response of 4.73. This association was also found for each drug independently. Moreover, in their study, no association of the 5-HTTLPR polymorphism with treatment response in the latter phase was observed, which is also in agreement with the results of our previous study. ${ }^{35}$ However, in the present study, both of 5-HTTLPR and 5-HT1A receptor $-1019 \mathrm{C} / \mathrm{G}$ polymorphisms were not associated with 12 months outcome of PAX treatment in PD.

This study is the first research that reported potential effect of EI by antidepressant to long-time outcome in PD. In MDDs, EI with antidepressants predicts later outcomes. ${ }^{30,32)}$ Additionally, EI at 1 week also predicts the response at 12 weeks to escitalopram, one of the SSRIs used for social anxiety disorder. ${ }^{38)}$ In the present study, EI could predict not only remission, but also discontinuation of PAX treatment in PD patients. The current results suggest a connection between EI and later therapeutic results that might be used to guide personalized medicine. In our results, being unmarried was also a risk factor for treatment discontinuation. Unmarried outpatients with PD might be less conservative and discontinue the treatment more easily than married outpatients.

Some patients discontinued the treatment after they achieved remission in the present study. Discontinuation of antidepressants within 12 months from initiation is thought to increase the risk of relapse in $\mathrm{PD},{ }^{39)}$ and continuing SSRIs pharmacotherapy for at least 1 year was also recommend. ${ }^{40)}$ At this point, PD patients who discontinue SSRIs within 1 year must be observed carefully.

Other factors such as sex, comorbid agoraphobia, comorbid MDD, comorbid physical illness, marital separation, alcohol, smoking did not determine 12 months therapeutic results in the present study.

There are several limitations in this study. The main limitation is that only two polymorphisms were assessed. Because PD is considered to be a polygenic disorder, ${ }^{17)}$ it is expected that other genes such as noradrenaline-related genes might contribute to PD pathogenesis and affect the clinical outcome of pharmacotherapy. Additionally, CGI scale is not a specified assessment scale for PD, unlike the
Panic and Agoraphobia observer-rated Scale. ${ }^{41)}$ However, it is an established research rating tool for psychiatric disorders that can be used by the practicing clinician to assess clinical severity and treatment effectiveness and that is the reason why it is used as main outcome in the present study and in previous researches of pharmacotherapy in PD. ${ }^{42,43)}$ Furthermore, the plasma concentration of PAX was not determined in this study. Therefore, the effects of PAX pharmacokinetics or non-adherence were not assessed. However, determination of the plasma concentration of PAX is not covered by the National Health Insurance of Japan. Finally, small sample size of this study is also a limitation.

In conclusion, EI achievement appears to be a determinant of remission in PAX treatment of PD outpatients. In married PD outpatients, EI achievement also appears to reduce a risk of discontinuation of PAX treatment. However, in unmarried outpatients, this effect of EI is not recognized.

\section{- Acknowledgments}

Kazutaka Shimoda has received research support from Daiichi Sankyo Co., Dainippon Sumitomo Pharma Co., Ltd., Eisai Co., Ltd., Eli Lilly Japan, K.K., GlaxoSmithKlein K.K., Meiji Seika Pharma Co., Ltd., Novartis Pharma K.K., Otsuka Pharmaceutical Co., Ltd., Pfizer Inc., Shionogi \& Co., Ltd., Takeda Pharmaceutical Co., Ltd., Tsumra \& Co., and Yoshitomi Pharmaceutical Industries, Ltd., and honoraria from Asahi Kasei Pharma Corporation, Astellas Pharma Inc., Daiichi Sankyo Co., Dainippon Sumitomo Pharma Co., Ltd., Eisai Co., Ltd., Eli Lilly Japan, K.K., GlaxoSmithKlein K.K., Janssen Pharmaceutical K.K, Kowa Pharmaceutical Co., Ltd., Meiji Seika Pharma Co., Mitsubishi Tanabe Pharma Corporation, Ltd., MSD K.K., Novartis Pharma K.K., Ono Pharmaceutical Co., Ltd., Pfizer Inc., Shionogi \& Co., Ltd., Takeda Pharmaceutical Co., Ltd., and Tsumra \& Co., from the year of 2012 to 2014. The authors other than Kazutaka Shimoda declare no biomedical or financial interests or potential conflicts of interest directly relevant to the content of the present study.

This study was funded by a Grant-in-Aid for Scientific Research (KAKENHI) from the Japan Society for the Promotion of Research (\#25461739) and Seki Minato Memorial Awards to Kazutaka Shimoda. The funding sources played no role in the study design; collection, analysis, or interpretation of data; writing of the report; or decision to submit the paper for publication. 


\section{REFERENCES}

1. Kessler RC, Chiu WT, Jin R, Ruscio AM, Shear K, Walters EE. The epidemiology of panic attacks, panic disorder, and agoraphobia in the National Comorbidity Survey Replication. Arch Gen Psychiatry 2006;63:415-424.

2. Carlbring P, Gustafsson H, Ekselius L, Andersson G. 12-month prevalence of panic disorder with or without agoraphobia in the Swedish general population. Soc Psychiatry Psychiatr Epidemiol 2002;37:207-211.

3. Crowe RR, Noyes R, Pauls DL, Slymen D. A family study of panic disorder. Arch Gen Psychiatry 1983;40:1065-1069.

4. Harris EL, Noyes R Jr, Crowe RR, Chaudhry DR. Family study of agoraphobia. Report of a pilot study. Arch Gen Psychiatry 1983;40:1061-1064.

5. Skre I, Onstad S, Torgersen S, Lygren S, Kringlen E. A twin study of DSM-III-R anxiety disorders. Acta Psychiatr Scand 1993;88:85-92.

6. Hettema JM, Neale MC, Kendler KS. A review and meta-analysis of the genetic epidemiology of anxiety disorders. Am J Psychiatry 2001;158:1568-1578.

7. Domschke K, Braun M, Ohrmann P, Suslow T, Kugel H, Bauer J, et al. Association of the functional $-1019 \mathrm{C} / \mathrm{G}$ 5-HT1A polymorphism with prefrontal cortex and amygdala activation measured with 3 T fMRI in panic disorder. Int $J$ Neuropsychopharmacol 2006;9:349-355.

8. Stahl SM. Independent actions on fear circuits may lead to therapeutic synergy for anxiety when combining serotonergic and GABAergic agents. J Clin Psychiatry 2002;63: 854-855.

9. Gross C, Zhuang X, Stark K, Ramboz S, Oosting R, Kirby $\mathrm{L}$, et al. Serotonin1A receptor acts during development to establish normal anxiety-like behaviour in the adult. Nature 2002;416:396-400.

10. Heils A, Teufel A, Petri S, Stöber G, Riederer P, Bengel $\mathrm{D}$, et al. Allelic variation of human serotonin transporter gene expression. J Neurochem 1996;66:2621-2624.

11. Deckert J, Catalano M, Heils A, Di Bella D, Friess F, Politi E, et al. Functional promoter polymorphism of the human serotonin transporter: lack of association with panic disorder. Psychiatr Genet 1997;7:45-47.

12. Hamilton SP, Heiman GA, Haghighi F, Mick S, Klein DF, Hodge SE, et al. Lack of genetic linkage or association between a functional serotonin transporter polymorphism and panic disorder. Psychiatr Genet 1999;9:1-6.

13. Ishiguro $\mathrm{H}$, Arinami $\mathrm{T}$, Yamada $\mathrm{K}$, Otsuka $\mathrm{Y}$, Toru $\mathrm{M}$, Shibuya H. An association study between a transcriptional polymorphism in the serotonin transporter gene and panic disorder in a Japanese population. Psychiatry Clin Neurosci 1997;51:333-335.

14. Olesen OF, Bennike B, Hansen ES, Koefoed P, Woldbye $\mathrm{DP}$, Bolwig TG, et al. The short/long polymorphism in the serotonin transporter gene promoter is not associated with panic disorder in a Scandinavian sample. Psychiatr Genet 2005; 15:159.

15. Blaya C, Salum GA, Lima MS, Leistner-Segal S, Manfro GG. Lack of association between the serotonin transporter promoter polymorphism (5-HTTLPR) and panic disorder: a systematic review and meta-analysis. Behav Brain Funct 2007;3:41.

16. Le François B, Czesak M, Steubl D, Albert PR. Transcriptional regulation at a HTR1A polymorphism associated with mental illness. Neuropharmacology 2008;55:977-985.

17. Freitag CM, Domschke K, Rothe C, Lee YJ, Hohoff C, Gutknecht $\mathrm{L}$, et al. Interaction of serotonergic and noradrenergic gene variants in panic disorder. Psychiatr Genet 2006;16:59-65.

18. Rothe C, Gutknecht L, Freitag C, Tauber R, Mössner R, Franke $\mathrm{P}$, et al. Association of a functional 1019C $>G$ 5-HT1A receptor gene polymorphism with panic disorder with agoraphobia. Int J Neuropsychopharmacol 2004;7: 189-192.

19. Faravelli C, Webb T, Ambonetti A, Fonnesu F, Sessarego A. Prevalence of traumatic early life events in 31 agoraphobic patients with panic attacks. Am J Psychiatry 1985; 142:1493-1494.

20. Faravelli C, Pallanti S. Recent life events and panic disorder. Am J Psychiatry 1989;146:622-626.

21. Chou KL. Panic disorder in older adults: evidence from the national epidemiologic survey on alcohol and related conditions. Int J Geriatr Psychiatry 2010;25:822-832.

22. Marcaurelle R, Bélanger C, Marchand A, Katerelos TE, Mainguy N. Marital predictors of symptom severity in panic disorder with agoraphobia. J Anxiety Disord 2005;19:211232.

23. Manuck SB, Bleil ME, Petersen KL, Flory JD, Mann JJ, Ferrell RE, et al. The socio-economic status of communities predicts variation in brain serotonergic responsivity. Psychol Med 2005;35:519-528.

24. Choe AY, Kim B, Lee KS, Lee JE, Lee JY, Choi TK, et al. Serotonergic genes (5-HTT and HTR1A) and separation life events: gene-by-environment interaction for panic disorder. Neuropsychobiology 2013;67:192-200.

25. Mojtabai R, Stuart EA, Hwang I, Eaton WW, Sampson N, Kessler RC. Long-term effects of mental disorders on educational attainment in the National Comorbidity Survey ten-year follow-up. Soc Psychiatry Psychiatr Epidemiol 2015;50:1577-1591.

26. Bakhshaie J, Zvolensky MJ, Goodwin RD. Cigarette smoking and the onset and persistence of panic attacks during mid-adulthood in the United States: 1994-2005. J Clin Psychiatry 2016;77:e21-e24.

27. Kim B, Shin WS, Kim MK, Lee SH. White matter microstructural changes are associated with alcohol use in patients with panic disorder. J Affect Disord 2016;199: 65-72.

28. Perna G, Favaron E, Di Bella D, Bussi R, Bellodi L. Antipanic efficacy of paroxetine and polymorphism within the promoter of the serotonin transporter gene. Neuropsychopharmacology 2005;30:2230-2235.

29. Yevtushenko OO, Oros MM, Reynolds GP. Early response to selective serotonin reuptake inhibitors in panic disorder is associated with a functional 5-HT1A receptor gene polymorphism. J Affect Disord 2010;123:308-311.

30. Szegedi A, Jansen WT, van Willigenburg AP, van der Meulen E, Stassen HH, Thase ME. Early improvement in the first 2 weeks as a predictor of treatment outcome in patients with major depressive disorder: a meta-analysis including 6562 patients. J Clin Psychiatry 2009;70:344-353.

31. Cusin C, Fava M, Amsterdam JD, Quitkin FM, Reimherr FW, Beasley CM Jr, et al. Early symptomatic worsening during treatment with fluoxetine in major depressive disorder: prevalence and implications. J Clin Psychiatry 2007;68:52-57.

32. Kato M, Serretti A, Nonen S, Takekita Y, Wakeno M, Azuma J, et al. Genetic variants in combination with early partial improvement as a clinical utility predictor of treatment outcome in major depressive disorder: the result of two pooled RCTs. Transl Psychiatry 2015;5:e513.

33. Guy W. ECDEU assessment manual for psychopharmacology. 
Rockville, MD.:U.S. Dept. of Health, Education, and Welfare, Public Health Service, Alcohol, Drug Abuse, and Mental Health Administration, National Institute of Mental Health, Psychopharmacology Research Branch, Division of Extramural Research Programs;1976. 616 p.

34. Aoki A, Ishiguro S, Watanabe T, Ueda M, Hayashi Y, Akiyama K, et al. Factors affecting discontinuation of initial treatment with paroxetine in panic disorder and major depressive disorder. Neuropsychiatr Dis Treat 2014;10: 1793-1798.

35. Ishiguro S, Watanabe T, Ueda M, Saeki Y, Hayashi Y, Akiyama K, et al. Determinants of pharmacodynamic trajectory of the therapeutic response to paroxetine in Japanese patients with panic disorder. Eur J Clin Pharmacol 2011; 67:1213-1221.

36. Han KM, Won E, Paik JW, Lee MS, Lee HW, Ham BJ. Mental health service use in adults with suicidal ideation within a nationally representative sample of the Korean population. J Affect Disord 2016;193:339-347.

37. Lesch KP, Bengel D, Heils A, Sabol SZ, Greenberg BD, Petri S, et al. Association of anxiety-related traits with a polymorphism in the serotonin transporter gene regulatory region. Science 1996;274:1527-1531.

38. Oh KS, Shin E, Ha J, Shin D, Shin Y, Lim SW. Early improvement in one week predicts the treatment response to escitalopram in patients with social anxiety disorder: a preliminary study. Clin Psychopharmacol Neurosci 2016; 14:161-167.

39. Mavissakalian MR, Perel JM. Long-term maintenance and discontinuation of imipramine therapy in panic disorder with agoraphobia. Arch Gen Psychiatry 1999;56:821-827.

40. Choi KW, Woo JM, Kim YR, Lee SH, Lee SY, Kim EJ, et al. Long-term escitalopram treatment in Korean patients with panic disorder: a prospective, naturalistic, open-label, multicenter trial. Clin Psychopharmacol Neurosci 2012;10: 44-48.

41. Bandelow B. Assessing the efficacy of treatments for panic disorder and agoraphobia. II. The Panic and Agoraphobia Scale. Int Clin Psychopharmacol 1995;10:73-81.

42. Nardi AE, Freire RC, Mochcovitch MD, Amrein R, Levitan $\mathrm{MN}$, King $\mathrm{AL}$, et al. A randomized, naturalistic, parallelgroup study for the long-term treatment of panic disorder with clonazepam or paroxetine. J Clin Psychopharmacol 2012;32:120-126.

43. Uguz F, Sahingoz M, Gungor B, Askin R. Low-dose imipramine for treatment of panic disorder during pregnancy: a retrospective chart review. J Clin Psychopharmacol 2014;34:513-515. 